\title{
Diagnostic efficacy of monoclonal antibody based sandwich enzyme linked immunosorbent assay (ELISA) for detection of Fasciola gigantica excretory/ secretory antigens in both serum and stool
}

Zeinab A Demerdash', Tarek M Diab², Ibrahim R Aly², Salwa H Mohamed', Faten S Mahmoud', Mona K Zoheiry', Wafaa A Mansour ${ }^{1}$, Mohy E Attia ${ }^{3}$ and Azza E El-Bassiouny ${ }^{1}$

\begin{abstract}
Background: This research was carried out to develop a reliable monoclonal antibody (MoAb)-based sandwich enzyme linked immunosorbent assay (ELISA) for the diagnosis of active Fasciola gigantica infection in both serum and stool for comparative purposes.

Methods: From a panel of MoAbs raised against F. gigantica excretory/secretory antigens (ES Ags), a pair (12B/ $11 \mathrm{D} / 3 \mathrm{~F}$ and $10 \mathrm{~A} / 9 \mathrm{D} / 10 \mathrm{G}$ ) was chosen due to its high reactivity and strict specificity to F. gigantica antigen by indirect ELISA.

Results: The two MoAbs were of the $\lg G_{1}$ and $\lg _{2 a}$ subclasses, respectively. Using SDS-PAGE and EITB, the selected MoAbs recognized 83, 64, 45 and $26 \mathrm{kDa}$ bands of ES Ags. The lower detection limit of ELISA assay was 3 $\mathrm{ng} / \mathrm{ml}$. In stool, the sensitivity, specificity and diagnostic efficacy of ELISA was 96\%, 98.2 and $97.1 \%$; while in serum they were 94\%, 94.6\% and 94.3\%, respectively. Moreover, a positive correlation was found between ova count in stool of $F$. gigantica infected patients and the OD readings of ELISA in both stool and serum samples $(r=0.730, p$ $<0.01$ and $r=0.608 ; p<0.01$, respectively).

Conclusions: These data showed that the use of MoAb-based sandwich ELISA for the detection of F. gigantica coproantigens in stool specimens was superior to serum samples; it provides a highly efficient, non-invasive technique for the diagnosis of active F. gigantica infection.
\end{abstract}

Keywords: Fasciola gigantica, Monoclonal antibodies, Sandwich ELISA, Coproantigen, Seroantigen

\section{Background}

Fasciola hepatica and F. gigantica are two trematode species which have an important impact on public health due to the infections they cause in humans and livestock. F. hepatica has a cosmopolitan distribution, mainly in temperate zones, while $F$. gigantica is found in tropical regions of Africa and Asia [1-3]. Although the majority of cases are attributed to $F$. hepatica, human infections with $F$. gigantica are also present in many countries [4-6]. In the Nile Delta of Egypt, beside the

\footnotetext{
* Correspondence: tarekmdiab@yahoo.com

2Department of Parasitology, Theodor Bilharz Research Institute, Giza, Egypt Full list of author information is available at the end of the article
}

two species, a third intermediate form of Fasciola sp. has been identified [3] using molecular approaches [7].

Parasitological diagnosis of human fascioliasis is often unreliable and has low sensitivity, as parasite eggs are not found during the pre-patent period and shedding of parasitic eggs is intermittent [8-10]. Moreover, Fasciola eggs may be found in the stools of uninfected persons who have eaten raw infected liver leading to false positive diagnosis [11]. Alternatively, detection of circulating Fasciola antigen in both serum and stool was found to be more sensitive and specific [12]. The majority of methods based on antigen detection are applied to $F$. hepatica infection, but only few are applied to F. gigantica infection [13-15]. 
This research was carried out to establish a highly efficient MoAb-based sandwich ELISA to diagnose active $F$. gigantica infection by detecting excretory/secretory antigens (ES Ags) in both serum and stool samples of infected patients for comparative purposes.

\section{Methods}

\section{Study Population}

Patients admitted to Gastroenterology and Hepatology Department, Theodor Bilharz Research Institute (TBRI), who complained of abdominal pain, loss of body weight, dyspepsia, fever and diarrhea were subjected to parasitological stool examination on three consecutive days using merthiolate-iodine-formaldehyde concentration method [16]. The number of eggs per gram stool was determined by the modified Katothick smear technique [17]. Three groups were used; F. gigantica infected group where patients had the characteristic large operculated Fasciola eggs in their stool samples with no evidence of other parasitic infections $(\mathrm{n}=50)$. Other parasites group $(\mathrm{n}=60)$ included S. mansoni $(\mathrm{n}=20)$, S. hematobium $(\mathrm{n}=20)$ and Hymenolepis nana $(\mathrm{n}=20)$. Control group ( $\mathrm{n}=$ 30) were age- and sex-matched parasite-free healthy individuals.

\section{Stool Elute Preparation and Serum Samples Collection}

Aqueous elutes of a portion of each stool specimen were prepared by adding approximately 3 parts of $0.01 \mathrm{M}$ phosphate-buffered saline (PBS), $\mathrm{pH} \mathrm{7.2,} \mathrm{containing}$ $0.05 \%$ Tween $20(\mathrm{PBS} / \mathrm{T})$ to 1 part of stool in a centrifuge tube [18]. The mixture was homogenized and then centrifuged at $900 \times g$ for $5 \mathrm{~min}$. The supernatant was aspirated and stored at $-80^{\circ} \mathrm{C}$ until use.

Whole blood was collected from each subject and centrifuged at $760 \times \mathrm{g}$ at $4^{\circ} \mathrm{C}$ for 10 minutes and the obtained serum samples were stored at $-80^{\circ} \mathrm{C}$ until use.

\section{Fasciola Excretory/Secretory (ES) Antigens}

Livers of infected cattle were obtained from a local abattoir at Giza District, Egypt. Live intact F. gigantica adult worms were collected from the bile ducts and thoroughly washed at room temperature with $0.9 \%$ sodium chloride. The worms were individually incubated at $37^{\circ}$ $\mathrm{C}$ in $5 \mathrm{ml}$ RPMI 1640 medium, pH 7.4, supplemented with $100 \mathrm{U}$ of penicillin and $100 \mu \mathrm{g}$ of streptomycin per ml medium (Sigma Chemicals, St. Louis, USA). Following $24 \mathrm{~h}$ incubation, the medium was centrifuged at $1500 \times g$ for $10 \mathrm{~min}$ at $4^{\circ} \mathrm{C}$. The supernatants containing the ES Ags were aspirated [19] and filtered using filter paper No. 1 and $0.22 \mathrm{~mm}$ filter membrane (Millipore, Bedford, MA). The protein content was determined using Bio-Rad assay kit. Supernatants were stored at $-20^{\circ} \mathrm{C}$ until use.

\section{Development of MoAbs against ES Ags}

BALB/c mice were immunized with $F$. gigantica ES Ags [20]. Immune splenocytes were fused with non-secreting murine myeloma cells $(\mathrm{P} 3 \times 63 \mathrm{Ag} .8)$ in the presence of $43 \%$ polyethylene glycol (Sigma) [21]. Hybridomas were screened for anti-Fasciola antibodies by ELISA, and highly reactive hybrids were cloned by limiting dilution using a splenocyte feeder layer. Specificity was determined by indirect ELISA [22] against S. mansoni SEA and E. granulosus antigens. MoAbs showing nocross reactivity with other parasites were selected. Hybridoma cells were injected intraperitoneally into $\mathrm{BALB} / \mathrm{c}$ mice for large-scale production of MoAbs.

\section{Isotypic Analysis of MoAbs}

Determination of MoAb isotype was done by indirect ELISA using ELISA plates coated with $20 \mu \mathrm{g} / \mathrm{ml}$ of $F$. gigantica ES Ags and a panel of goat anti-mouse peroxidase-conjugated immunoglobulins (IgM, IgG, IgG ${ }_{1}$, $\operatorname{IgG}_{2 \mathrm{a}}, \operatorname{Ig}_{2 \mathrm{~b}}, \operatorname{IgG}_{3}$ and IgA, Sigma).

\section{Characterization of Target Antigen}

Sodium dodecylsulphate-polyacrilamide gel electrophoresis (SDS-PAGE) and Immunoblot was carried out as described by Laemmli [23]. F. gigantica ES antigens was fractionated on $12.5 \%$ SDS-PAGE and either stained with Commassie brilliant blue $0.05 \%$ or transferred into nitrocellulose membrane and probed with peroxidaseconjugated IgG MoAb [24,25]. The chemical nature of MoAb-recognized epitopes was defined by testing the reactivity of target antigens by indirect ELISA before and after $20 \mathrm{mM}$ sodium periodate treatment [26].

\section{Purification and Conjugation of MoAbs}

Selected MoAbs of IgG class were purified by ammonium sulfate precipitation, dialyzed against an excess of PBS and passed through a prepacked Mono-Q-HR 5/5 column (ion exchange chromatography) [27]. The antigen detecting MoAb was conjugated to horseradish peroxidase (type VI; Sigma) [28].

\section{Detection of circulating Fasciola antigen (CFA) in both serum and stool by MoAb-based sandwich ELISA}

The following sandwich-ELISA was adopted using a pair of MoAbs against ES Ags, 12B/11D/3F as antigen capturing and 10A/9D/10G as antigen detecting antibody. The optimal dilutions of MoAbs were determined by a checkerboard titration using a negative- and positivecontrol serum and stool samples in each plate. For each step, $100 \mu \mathrm{l} /$ well was added unless mentioned otherwise. Polystyrene microtiter plates (Thomas Scientific, USA) were sensitized overnight at room temperature with purified $12 \mathrm{~B} / 11 \mathrm{D} / 3 \mathrm{~F}$ MoAb $(5 \mu \mathrm{g} / \mathrm{ml}$ of $0.1 \mathrm{M}$ carbonate buffer, $\mathrm{pH}$ 9.6). The plates were thoroughly washed with 
$\mathrm{PBS} / \mathrm{T}$ ( $2 \mathrm{~min} / \mathrm{wash}$ ), and unbound sites were blocked with $200 \mu \mathrm{l} /$ well of $2.5 \%$ fetal calf serum (Sigma) diluted in $\mathrm{PBS} / \mathrm{T}, \mathrm{pH}$ 7.4. After $2 \mathrm{~h}$ incubation at $37^{\circ} \mathrm{C}$, the plates were emptied by suction. Undiluted serum and stool elutes were added (undiluted) and the plates were incubated for $1 \mathrm{~h}$ at $37^{\circ} \mathrm{C}$. After thorough washing as described above, peroxidase-conjugated 10A/9D/10G $\operatorname{MoAb}(10 \mu \mathrm{g} / \mathrm{ml}$ of $\mathrm{PBS} / \mathrm{T})$ was added. The plates were incubated for $1 \mathrm{~h}$ at $37^{\circ} \mathrm{C}$ and washed with PBS/T. The substrate $O$-phenylenediamine dihydrochloride (Sigma) was added and the plates were incubated for 30 minutes in the dark at room temperature. The enzyme reaction was stopped with $50 \mu \mathrm{l} /$ well of $8 \mathrm{~N} \mathrm{H}_{2} \mathrm{SO}_{4}$. The absorbance at $492 \mathrm{~nm}$ wavelength $\left(A_{492}\right)$ of the plates was read using a microplate ELISA reader (Bio-Rad, Richmond CA, USA).

\section{Statistical analysis}

Data were expressed as mean \pm standard deviation. Standard diagnostic indices including sensitivity, specificity and diagnostic efficacy were calculated as described by Galen [29]. Correlations between different parameters were performed using Pearson correlation coefficient. P value greater than 0.05 was considered not significant and less than 0.01 was considered highly significant. SPSS computer program (version 12 windows) was used for data analysis.

\section{Ethical considerations}

This study was conducted on patients admitted to Theodore Bilharz Research Institute after approval of the institutional ethical committee and obtaining an informed consent from every patient.

\section{Results}

The SDS-PAGE analysis and Coomassie brilliant blue staining of $F$. gigantica ES Ags are shown in Figure 1. The fractionated ES Ags containing several bands ranged from 14 to $100 \mathrm{kDs}$.

\section{Sensitivity, Specificity and Characterization of MoAbs}

From a panel of MoAbs raised against F. gigantica ES products, a pair $(12 \mathrm{~B} / 11 \mathrm{D} / 3 \mathrm{~F}$ and $10 \mathrm{~A} / 9 \mathrm{D} / 10 \mathrm{G})$ was selected due to their high reactivity to $F$. gigantica antigen by indirect ELISA. Both MoAbs showed no crossreactions with S. mansoni, S. hematobium or H. nana antigens. Isotypic analysis of the $12 \mathrm{~B} / 11 \mathrm{D} / 3 \mathrm{~F}$ and $10 \mathrm{~A} /$ 9D/10G MoAbs revealed that they were of $\mathrm{IgG}_{1}$ and $\mathrm{IgG}_{2}$ subclasses, respectively. The enzyme-linked immunoelectrotransfer blot (EITB) technique revealed that the two selected MoAbs recognized 83, 64, 45 and 26 $\mathrm{kDa}$ bands of electrophorsed ES Ag (Figure 2). The chemical nature of MoAbs-recognized epitopes was defined following $20 \mathrm{mM}$ sodium periodate treatment of target

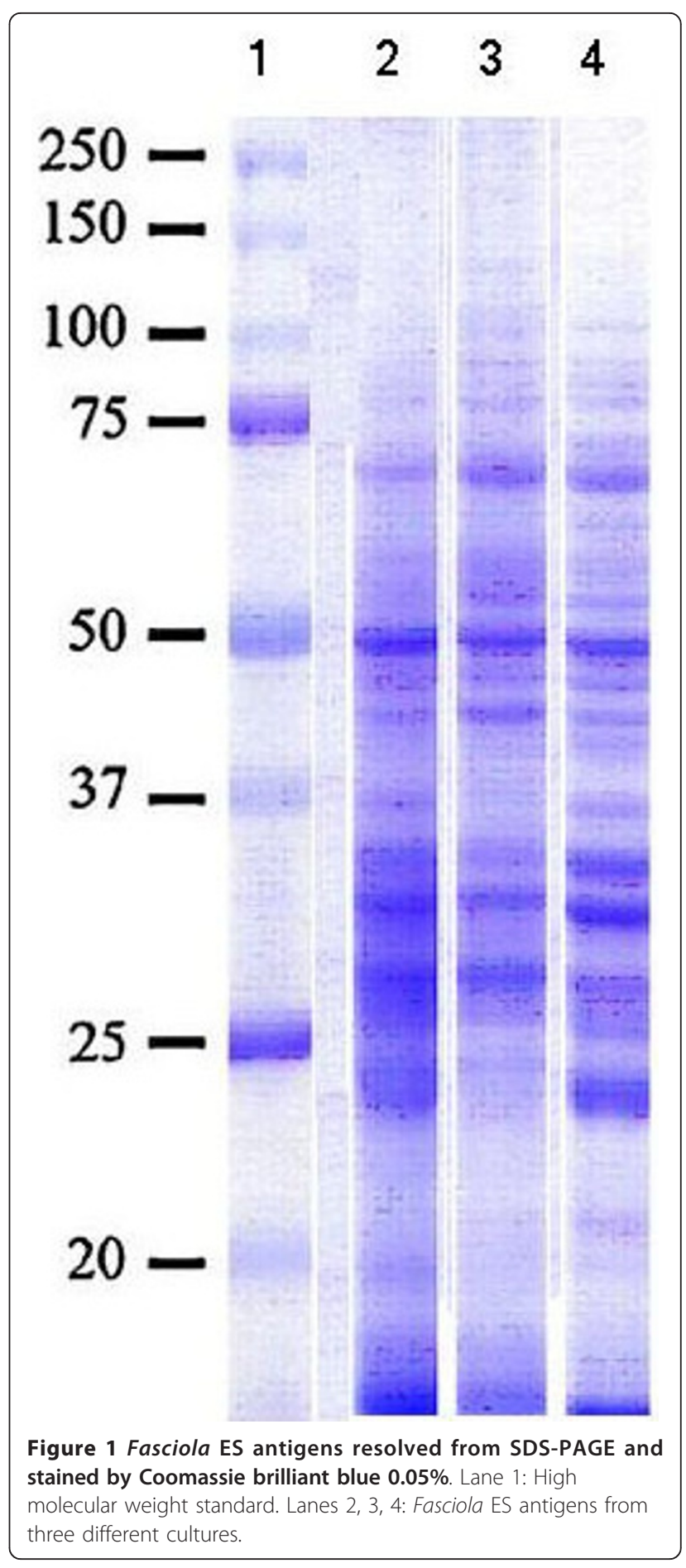

antigen. Marked reduction in MoAbs' reactivity was detected (Table 1), denoting that the reactive epitopes were glycoprotein in nature.

\section{MoAb-Sandwich ELISA}

From the standard curve, the lower detection limit of ELISA assay was $3 \mathrm{ng} / \mathrm{ml}$. The cut- off value was 


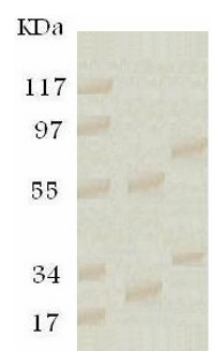

Figure 2 Enzyme-linked immunoelectrotransfer blot of purified Fasciola ES antigen resolved on $12.5 \%$ SDS-PAGE and probed with a pair of MoAbs against ES products. Lane 1: Low molecular weight standard. Lane 2: The 10A/9D/10G MoAb. Lane 3: The 12B/11D/3F MoAb.

calculated as the mean OD reading of negative controls +2 standard deviation of the mean. The OD readings equal to or less than cut- off value were considered negative while those readings greater than the cut off value were considered positive. The specificity of the assay was determined as the sum of results of negative control group and other parasites group.

In serum, the cut-off value was 0.263 and ES Ag was detected in 47 out of 50 Fasciola-infected patients and the sensitivity of the assay was $94 \%$ while in stool elutes the cut-off value was 0.294 and 48 out of 50 Fasciolainfected patients were positive, yielding a sensitivity of 96\%. All the 20 negative controls had ES Ag levels below the cut-off value in both serum and stool samples. Furthermore, 32 out of 35 serum samples and 34 out of 35 stool elutes belonging to patients harboring other parasites had undetectable ES Ag of Fasciola leading to overall specificity $94.6 \%(52 / 55)$ and $98.2 \%$ (54/ $55)$ in serum and stool samples, respectively. The diagnostic efficacy of the assay was $94.3 \%$ and $97.1 \%$, respectively (Figures 3,4 ).

A positive correlation was found between ova count in stools of Fasciola-infected patients and the OD readings of ELISA in both stool and serum samples $(r=0.730, p$ $<0.001$ and $\mathrm{r}=0.608 ; \mathrm{p}<0.001$, respectively).

\section{Discussion}

In this study, a MoAb-based sandwich ELISA was employed for detection of circulating $F$. gigantica ES Ags in both serum and stool samples of $F$. gigantica

Table 1 Impact of ES antigen treatment with $20 \mathrm{mM}$ sodium periodate on MoAbs' reactivity by indirect ELISA (OD = $492 \mathrm{~nm}$ )

\begin{tabular}{lccc}
\hline Target MoAbs & Before treatment & After treatment & \% Reduction \\
\hline 12B/11D/3F & $1.50 \pm 0.15$ & $0.71 \pm 0.12$ & $52.7 \%$ \\
\hline 10A/9D/10G & $1.35 \pm 0.12$ & $0.56 \pm 0.09$ & $58.5 \%$ \\
\hline
\end{tabular}

Data are expressed as mean \pm standard deviation or percent. infected patients. Identification of the target antigens recognized by anti-Fasciola MoAbs $(12 \mathrm{~B} / 11 \mathrm{D} / 3 \mathrm{~F}$ and $10 \mathrm{~A} / 9 \mathrm{D} / 10 \mathrm{D})$ showed that they were glycoproteins and their MW lay in the $83,64,45$ and $26 \mathrm{kDa}$ regions. Close to our findings, Arafa et al. [30] produced monospecific antibodies against ES Ags of F. gigantica whose target antigens were recognized at 27.5, 32.5 and $55 \mathrm{kDa}$ regions. They reported that cross reactivity with Schistosoma mansoni occurs at higher MW (110-120 kDa).

In the present study, our MoAbs were able to detect F. gigantica antigens level $\geq 3 \mathrm{ng} / \mathrm{ml}$ in sandwich ELISA. This could be attributed to the use of a pair of MoAbs, one as antigen capturing antibody $(12 \mathrm{~B} / 11 \mathrm{D} / 3 \mathrm{~F})$ which enhance the binding capacity of the other MoAb (10A/ 9D/10G) to the ES Ags that could help to reduce background and led to lowering the detection limit of these MoAbs. This detection limit is lower than those of Espino and Finlay [11] who detected Fasciola ES Ags in patients' stool at a concentration $>15 \mathrm{ng} / \mathrm{ml}$. Also, Anuracpreeda et al. [31] developed a MoAb-based sandwich ELISA for detection of $28.5 \mathrm{kDa}$ tegumental antigen (TA) in sera of mice experimentally infected with $F$. gigantica and found that the lower detection limit was $60 \mathrm{ng} / \mathrm{ml}$ for SE antigens, $16 \mathrm{ng} / \mathrm{ml}$ for whole body antigen, and $600 \mathrm{pg} / \mathrm{ml}$ for $28.5 \mathrm{kDa}$ TA.

In the present study, the sensitivity and specificity of MoAb-based ELISA in serum was $94 \%$ and $95.6 \%$, while in stool samples it was $96 \%$ and $98.2 \%$, respectively. A few antigen detection assays have been developed for diagnosis of $F$. gigantica in human fluids with varied ranges of sensitivities and specificities $[11,18,30]$. The difference in specificities could be attributed to the complex composition of ES that makes this antigenic preparation not amenable to compare its performance in ELISA results reported from different groups. This may be due to the different protocols used to prepare ES [32-34] or to the variation in its composition when obtained from parasites derived from different hosts [35], which is not the case when a purified antigen is used [36].

In this study, the diagnostic efficacy of MoAb-based sandwich ELISA in stool (coproantigens) was superior to serum samples (97.1\% vs $94.3 \%$ ); this could be due to the fact that coproantigens offered several advantages, e. g., the levels of coproantigens are less affected by immune complex formation than circulating Fasciola antigens, coproantigens are detectable during prepatent and patent phases of infection, non-invasive and finally the nature of these antigens of being glycoprotein making the coproantigen stable under several different storage conditions which ensured its diagnostic value $[11,18,31,37,38]$.

A positive correlation was found between ova count/ gm stool of Fasciola infected patients and the OD 


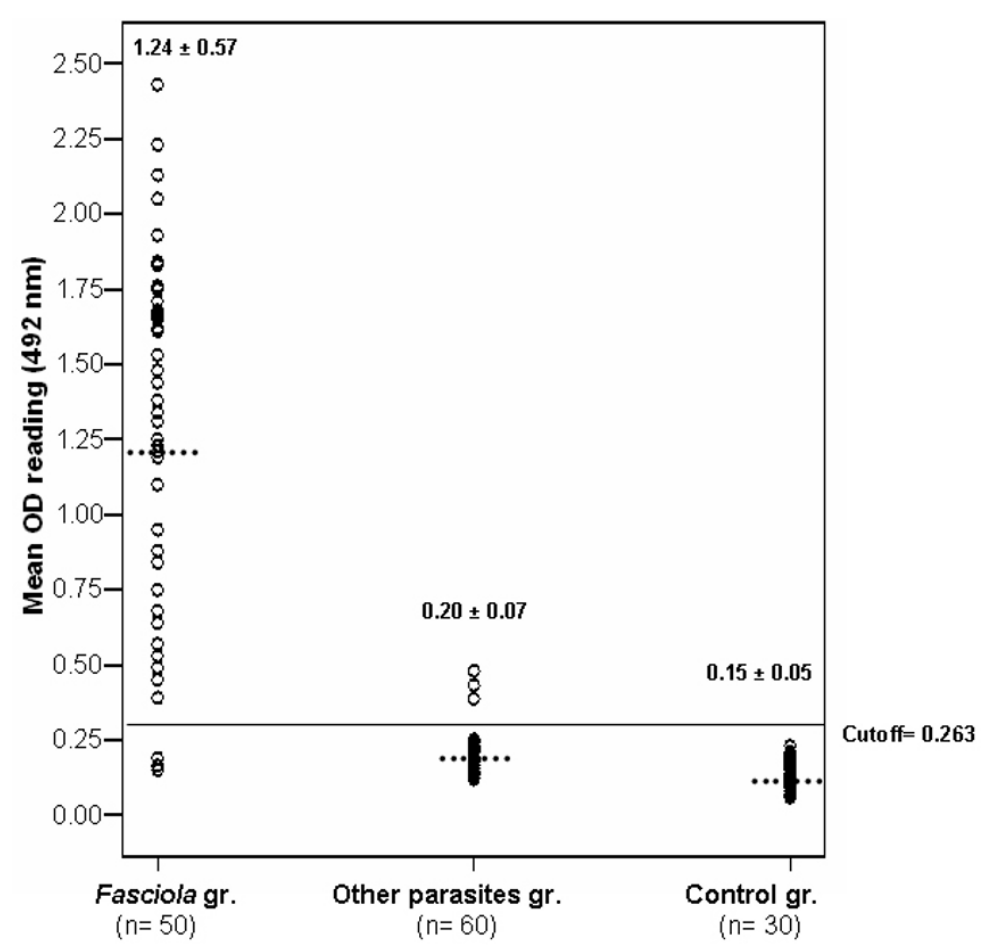

Figure 3 Level of Fasciola ES antigen detected in serum samples of different studied groups measured by sandwich ELISA (OD reading at $492 \mathrm{~nm}$ ). The horizontal line represents the cut-off value of the assay (the lower detection limit). Dotted lines represent the mean OD value.

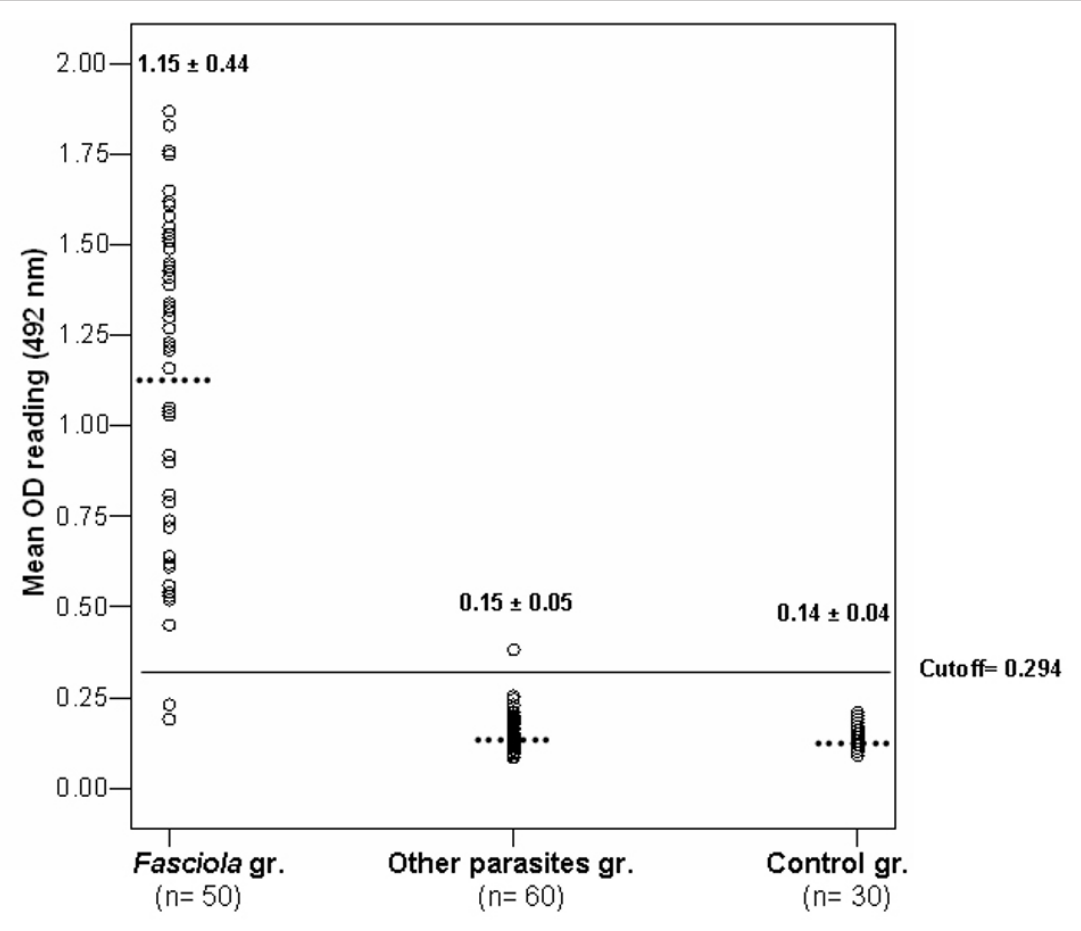

Figure 4 Level of Fasciola ES antigen detected in stool samples of different studied groups measured by sandwich ELISA (OD reading at $492 \mathrm{~nm}$ ). The horizontal line represents the cut-off value of the assay (the lower detection limit). Dotted lines represent the mean OD value. 
readings of ELISA in both stool and serum samples. Other studies have demonstrated that coproantigens are correlated with Fasciola egg counts [11] and the parasite burden $[31,39,40]$. As the fecal egg count is presumably dependent on the number of flukes in the host, one can postulate that stool antigen level in patients infected with Fasciola are directly related to the number of adult parasites. Therefore, the absence of coproantigen in one of our patients may be due to a very light parasite burden and consequently undetectable levels of antigens in stools $[14,18]$. On the other hand, Ubeira et al. [32] reported that there was no correlation between number of ova/gm stool and coproantigens levels measured by ELISA.

\section{Conclusion}

Our results provide evidence that detection of ES antigens in stool specimens improves and simplifies the diagnosis of $F$. gigantica infection in human. By using this assay, the presence of ES Ags was easily demonstrated in most of the stool specimens from patients with confirmed $F$. gigantica presenting a reliable, noninvasive diagnostic method for active infection.

\section{Acknowledgements}

This work was supported by internal project No. 65 D at Theodor Bilharz Research Institute and supported in part by ASTF project No. 66, Egypt.

\section{Author details}

'Department of Immunology, Theodor Bilharz Research Institute, Giza, Egypt. 2Department of Parasitology, Theodor Bilharz Research Institute, Giza, Egypt. ${ }^{3}$ Department of Gastroenterology and Hepatology, Theodor Bilharz Research Institute, Giza, Egypt.

\section{Authors' contributions}

Both ZAD and AEE designed the study. ZAD, AEE, SHM, FSM, WAM, IRA and MKZ developed the MoAbs-based sandwich ELISA. MEA performed the clinical examinations to subjects of the study IRA and TMD collected the samples, performed the parasitological examinations and evaluated the diagnostic efficacy of the assay. TMD collected the data and performed the statistical analysis. All the authors discussed, revised, read and approved the final manuscript.

\section{Competing interests}

The authors declare that they have no competing interests.

Received: 6 June 2011 Accepted: 15 September 2011 Published: 15 September 2011

\section{References}

1. Torgerson P, Claxton J: Epidemiology and control. In Fasciolosis. Edited by: Dalton JP. CABI Publishing, Oxon, UK; 1999:113-149.

2. Mas-Coma S, Bargues M, Valero M: Fascioliasis and other plant-borne trematode zoonoses. Int J Parasitol 2005, 35:1255-78.

3. Mas-Coma S, Valero MA, Bargues MD: Chapter 2. Fasciola, lymnaeids and human fascioliasis, with a global overview on disease transmission, epidemiology, evolutionary genetics, molecular epidemiology and control. Adv Parasitol 2009, 69:41-146.

4. Ashrafi K, Valero MA, Massoud J, Sobhani A, Solaymani-Mohammadi S, Conde $\mathrm{P}$, Khoubbane M, Bargues MD, Mas-Coma S: Plant-borne human contamination by fascioliasis. Am J Trop Med Hyg 2006, 75:295-302.
5. Ashrafi K, Valero MA, Panova M, Periago MV, Massoud J, Mas-Coma S: Phenotypic analysis of adults of Fasciola hepatica, Fasciola gigantica and intermediate forms from the endemic region of Gilan. Iran Parasitol Int 2006, 55:249-260.

6. Le TH, De NV, Agatsuma T, Blair D, Vercruysse J, Dorny P, Nguyen TG, McManus DP: Molecular confirmation that Fasciola gigantica can undertake aberrant migrations in human hosts. J Clin Microbiol 2007, 45:648-650.

7. Lin Ai, Chen Mu-Xin, Alasaad Samer, Elsheikha MHany, Li Juan, Li Hai-Long Lin Rui-Qing, Zou Feng-Cai, Zhu Xing-Quan, Chen Jia-Xu: Genetic characterization, species differentiation and detection of Fasciola spp. by molecular approaches. Parasit Vectors 2011, 4:101.

8. Ghosh S, Rawat P, Velusamy R, Joseph D, Gupta SC, Singh BP: 27 kDa Fasciola gigantica glycoprotein for the diagnosis of prepatent fasciolosis in cattle. Vet Res Commun 2005, 29:123-135.

9. Ghosh S, Rawat P, Gupta SC, Singh BP: Comparative diagnostic potentiality of ELISA and dot-ELISA in prepatent diagnosis of experimental Fasciola gigantica infection in cattle. Indian J Exp Biol 2005 , 43:536-541.

10. Kumar N, Ghosh S, Gupta SC: Early detection of Fasciola gigantica infection in buffaloes by enzyme-linked immunosorbent assay and dot enzyme-linked immunosorbent assay. Parasitol Res 2008, 103:141-150.

11. Espino A, Finlay C: Sandwich enzyme-liked immunosorbent assay for detection of excretory/secretory antigens in humans with fascioliasis. $J$ Clin Microbiol 1994, 32:190-3.

12. Hillyer GV: Immunodiagnosis of human and animal fasciolosis. In Fasciolosis. Edited by: Dalton JP. CABI Publishing, Oxon, U.K; 1999:435-447.

13. Estuningsih ES, Widjayanti S, Adiwinata G, Piedrafita D: Detection of coproantigens by sandwich ELISA in sheep experimentally infected with Fasciola gigantica. Trop Biomed 2004, 21(Suppl 2):51-56.

14. Mezo M, Gonzalez W, Carro C, Ubeira F: An ultra-sensitive capture ELISA for detection of Fasciola hepatica coproantigens in sheep and cattle using a new monoclonal antibody (MM3). J Parasitol 2004, 90:845-52.

15. Mezo M, González-Warleta M, Ubeira FM: The use of MM3 monoclonal antibodies for early immunodiagnosis of ovine fascioliasis. J Parasitol 2007, 93:65-72.

16. Sapero JJ, Lawless DK: The MIF stain preservative technique for the identification of intestinal parasites. Am J Trop Med Hyg 1953, 2:613-619.

17. Siongok TKA, Mahmoud AAF, Guma JH, Warren KS, Muller AS, Handa AK, Houser HB: Morbidity in schistosomiasis mansoni in relation to intensity of infection: A study of a community in Machakos, Kenya. Am J Trop Med Hyg 1976, 25:273-284.

18. Espino A, Diaz A, Perez A, Carlos M: Dynamics of antigenemia and coproantigens during a human Fasciola hepatica outbreak. J Clin Microbiol 1998, 36:2723-6.

19. Dalton JP, Heffernan M: Thiol protease released in vitro by Fasciola hepatica. Mol Biochem Parasitol 1989, 35:161-6.

20. Cianfriglia M, Armellini D, Massone A, Mariani M: Simple immunization protocol for high frequency production of soluble antigen specific hybridomas. Hybridoma 1983, 2:451-7.

21. Galfre G, Milstein C: Properties of monoclonal antibodies: Strategies and procedures. Meth Enzymol 1981, 73:3-46.

22. Demerdash Z, Mahmoud S, Shaker Z, Hassan S, Mansour M: Detection of circulating schistosome antigens in serum and urine of schistosomiasis patients and assessment of cure by a monoclonal antibody. J Egypt SoC Parasitol 1995, 25:471-84.

23. Laemmli U: Cleavage of structural proteins during the assembly of the head of bacteriophage T4. Nature 1970, 227:680-5.

24. Tsang V, Peralta J, Simons A: Enzyme-Linked Immunoelectro-Transfer Blot Techniques (EITB) for Studying the Specificities of Antigens and Antibodies Separated by Gel Electrophoresis. In Methods in Enzymology: Immunochemical Techniques. Edited by: Langone JJ, Vunakie HV. Academic Press, New York; 1983:337-91.

25. Abdel Rahman S, Malone J, O'reilly K: Biochemical characterization and localization of Fasciola hepatica 26-28 kDa diagnostic coproantigen. Parasite Immunol 1999, 21:279-86.

26. Woodward M, Young W, Bloodgood R: Detection of monoclonal antibodies specific for carbohydrate epitopes using periodate oxidation. J Immunol Meth 1985, 78:143-53.

27. Maizels RM, Robertson BD: Purification of Antigens and Antibodies. Imperial College of Science, Technology and Medicine, London; 31988. 
28. Tijssen P, Kurstak P: Highly efficient and simple methods for the preparation of peroxidase and active peroxidase-antibody conjugates for enzyme immunoassays. Anal Biochem 1984, 136:451-7.

29. Galen RS: Predictive values and efficiency of laboratory testing. Pediat J Clin North Am 1980, 27:861-69.

30. Arafa MS, Abaza SM, El-Shewy KA, Mohareb EW, El-Moamly AA: Detection of Fasciola-specific excretory/secretory (E/S) protein fraction band (49.5 $\mathrm{kDa}$ ) and its utilization in diagnosis of early fascioliasis using different diagnostic techniques. J Egypt Soc Parasitol 1999, 29(Suppl 3):911-26.

31. Anuracpreeda P, Wanichanon C, Chawengkirtikul R, Chaithirayanon K, Sobhon P: Fasciola gigantica: Immunodiagnosis of fasciolosis by detection of circulating $28.5 \mathrm{kDa}$ tegumental antigen. Exp Parasitol 2009, 123:334-340

32. Ubeira FM, Muiño L, Valero MA, Periago MV, Pérez-Crespo I, Mezo M, González-Warleta M, Romarís F, Paniagua E, Cortizo S, Llovo J, Más-Coma S: MM3-ELISA detection of Fasciola hepatica coproantigens in preserved human stool samples. Am J Trop Med Hyg 2009, 81(Suppl 1):156-62.

33. Cornelissen JB, de Leeuw WA, van der Heijden PJ: Comparison of an indirect haemagglutination assay and an ELISA for diagnosing Fasciola hepatica in experimentally and naturally infected sheep. Vet Quart 1992, 14:152-156.

34. Dumenigo BE, Espino AM, Finlay CM, Mezo M: Kinetics of antibody-based antigen detection in serum and faeces of sheep experimentally infected with Fasciola hepatica. Vet Parasitol 2000, 89:153-161.

35. Lee CG, Zimmerman GL, Wee SH: Fasciola hepatica: Comparison of flukes from Korea and the United States by isoelectric focusing banding patterns of whole-body protein. Vet Parasitol 1992, 42(Suppl 3-4):311-6.

36. Neyra V, Chavarry E, Espinoza JR: Cysteine proteinases Fas1 and Fas2 are diagnostic markers for Fasciola hepatica infection in alpacas (Lama pacos). Vet Parasitol 2002, 105:21-32.

37. Velusamy $R$, Singh BP, Sharma RL, Chanda D: Detection of circulating 54 $\mathrm{kDa}$ antigen in sera of bovine calves experimentally infected with $F$. gigantica. Vet Parasitol 2004, 119:187-195.

38. Valero MA, Ubeira FM, Khoubbane M, Artigas P, Muino L, Mezo M, PérezCrespo I, Periago MV, Mas-Coma S: MM3-ELISA evaluation of coproantigen release and serum antibody production in sheep experimentally infected with Fasciola hepatica and F. gigantica. Vet Parasitol 2009, 159:77-81.

39. Anuracpreeda P, Wanichanon C, Sobhon P: Fasciola gigantica: immunolocalization of $28.5 \mathrm{kDa}$ antigen in the tegument of metacercaria and juvenile fluke. Exp Parasitol 2009, 122:75-83.

40. Dumenigo B, Espino A, Finlay C: Detection of Fasciola hepatica antigens in cattle feces by a monoclonal antibody-based sandwich immunoassay. Res Vet Sci 1996, 60:278-9.

doi:10.1186/1756-3305-4-176

Cite this article as: Demerdash et al: Diagnostic efficacy of monoclonal antibody based sandwich enzyme linked immunosorbent assay (ELISA) for detection of Fasciola gigantica excretory/secretory antigens in both serum and stool. Parasites \& Vectors 2011 4:176.

\section{Submit your next manuscript to BioMed Central and take full advantage of:}

- Convenient online submission

- Thorough peer review

- No space constraints or color figure charges

- Immediate publication on acceptance

- Inclusion in PubMed, CAS, Scopus and Google Scholar

- Research which is freely available for redistribution 